\title{
Routine test batteries for cognitive impairment in older people may not be cost effective
}

\author{
Michael Marks core medical trainee
}

St Thomas' Hospital, London SE1 7EH, UK

Young and colleagues provide guidance on assessing cognitive impairment in older people, including the use of a battery of tests to establish the underlying cause. ${ }^{1}$ The value of such exhaustive test batteries, however, is not well validated.

Brodaty tested consecutive patients attending a memory disorders clinic. ${ }^{2}$ No patient had "significant relevant abnormalities" identified. Equivocal abnormalities of low vitamin $B_{12}$, folate, and thyroid function were each identified once in 13 patients. In no patients did treatment affect the course of cognitive decline. Computed tomography and electroencephalography seemed to have greater yield. Siu also found that, in the absence of evidence of deficiency, the yield of measuring vitamin $B_{12}$ in patients with a normal full blood count was minimal. ${ }^{3}$ VDRL testing was also of minimal value.

Another study found blood counts, thyroid function, calcium, and glucose valuable in assessing patients with dementia. ${ }^{4}$ Unselected vitamin $B_{12}$ testing cost $\$ 6426$ ( $£ 4117$; $€ 4752$ ) per diagnosis of vitamin $B_{12}$ deficiency. Testing only patients with abnormal full blood counts reduced this to $\$ 2260.42$ without affecting sensitivity. Folate deficiency was seen mainly in patients with abnormal blood counts; those with normal blood counts and low folate did not benefit from treatment. They estimated the cost of using exhaustive test batteries to assess 3 million people at $\$ 2.1-3 \mathrm{bn}$, or $\$ 450-630$ million for more selective testing.

This highlights the need to consider the yield of each test in the patient being assessed. Rates of diagnosis are similar for tailored testing rather than unselected test batteries, but costs are much lower.

Competing interests: None declared.

Young J, Meagher D, MacLullich A. Cognitive assessment of older people. BM 2011;343:d5042. (7 September.)

2 Brodaty H. Low diagnostic yield in a memory disorders clinic. Int Psychogeriatr 1990;2:149-59.

3 Siu A. Screening for dementia and investigating its causes. Ann Intern Med 1991;115:122-32.

4 Larson E, Reifler BV, Sumi SM, Canfield CG, Chinn NM. Diagnostic tests in the evaluation of dementia-a prospective study of 200 elderly outpatients. Arch Intern Med 1986;146:1917-22.

Cite this as: BMJ 2011;343:d6330

๑ $\mathrm{BMJ}$ Publishing Group Ltd 2011 